\title{
Solid pseudopapillary neoplasm of the pancreas
}

\author{
Donna Cummins, ${ }^{1}$ Margaret Sheehan, ${ }^{2}$ John Bruzzi, ${ }^{3}$ Oliver McAnena ${ }^{4}$ \\ ${ }^{1}$ Department of Emergency Medicine, Mater Misericordiae University Hospital, Dublin, Ireland; \\ 2Department of Pathology, National University of Ireland, Galway, Ireland; \\ ${ }^{3}$ Department of Radiology, University College Hospital, Galway, Galway, Ireland; \\ ${ }^{4}$ Department of Surgery, Galway University Hospital, Galway, Ireland \\ Correspondence to Dr Donna Cummins, donnacummins@gmail.com
}

\begin{abstract}
Summary
Solid pseudopapillary neoplasms (SPNs) are rare entities accounting for between 0.13 and 2.7 per cent of pancreatic tumours. This neoplasm has a predilection for females under the age of 35. The authors report this case of a SPN incidentally discovered when a 59-year-old female underwent a chest $x$-ray to investigate a wheeze. A subsequent CT abdomen revealed a $10 \mathrm{~cm}$ well-circumscribed mass adjacent to the tail of the pancreas. This mass was successfully resected. Immunohistochemical markers established the diagnosis of a SPN. The wheeze associated with the presentation of this case was unrelated to the tumour which was an incidental finding. These neoplasms are largely asymptomatic and indolent reaching a large size before detection. Diagnosis is confirmed on histology and in this case surgical resection was curative and there was no metastasis at presentation.
\end{abstract}

\section{BACKGROUND}

Solid pseudopapillary neoplasms (SPNs) are rare entities accounting for between 0.13 and 2.7 per cent of pancreatic tumours. ${ }^{1}$ Pancreatic cancer ranks as the fourth most common cancer type in the western world and is responsible for $6 \%$ of all cancer related deaths. ${ }^{2}$ The predominant pathological subtype is ductal adenocarcinoma, which accounts for over $90 \%$ of all pancreatic tumours. Pancreatic cysts may be either neoplastic or non-neoplastic. Pancreatic cystic neoplasms are categorised using the WHO histological classification: ${ }^{3}$

- Serous cystic tumours

- Mucinous cystic neoplasms

- Intraductal papillary mucinous neoplasms

- Solid pseudopapillary neoplasms (SPNs).

This case illustrates the elusive presentation associated with the rare SPN tumour category and describes the diagnostic and interventional strategy that can be applied in their management. This neoplasm had reached a significant size of $10 \mathrm{~cm}$ appreciable on radiological imaging and yet was asymptomatic and not palpable on physical examination. There are no large scale studies examining the malignant potential of these neoplasms and risk factors for this malignancy are unclear.

\section{CASE PRESENTATION}

A 59-year-old woman, presented to her general practitioner with a new onset respiratory wheeze. CXR revealed an incidental calcified node in the left upper abdominal quadrant. Her medical history was remarkable only for hypertension. Her family history was non-contributory and she had no prior abdominal surgery. She had no history of smoking and consumed between four and six units of alcohol per week. Review of systems was otherwise unremarkable. On examination, her vitals were stable. Her abdominal exam demonstrated tenderness felt in the left upper quadrant on deep palpation. Her presenting wheeze resolved without treatment. She underwent CT abdomen for further investigation of the calcified node incidentally seen on chest x-ray.

\section{INVESTIGATIONS}

CT abdomen (figure 1) showed a $10 \mathrm{~cm}$ mass adjacent to the greater curvature of the stomach anteriorly and the tail of the pancreas inferiorly. Areas of high attenuation were noted and, following administration of intravenous contrast, there was no detectable internal enhancement. The origin of the mass was unclear. It contained a thick rim of calcification and multiple internal calcified septa. The soft tissue had breached the internal capsule suggesting this mass had an aggressive component. Biochemical and haematological assays were normal.

\section{DIFFERENTIAL DIAGNOSIS}

On the basis of this presentation, the major differential diagnosis of these radiological findings included an exophytic leiomyoma, a neuroendocrine tumour, mucinous cystadenoma and a splenic artery aneurysm. An exophytic leiomyoma would be expected to become symptomatic at $10 \mathrm{~cm}$ and ulceration would be associated with this finding. The lack of tumour contrast enhancement made a neuroendocrine tumour an unlikely candidate. Clinically, most splenic artery aneursyms are asymptomatic and may be associated with calcification. However, on imaging, the tumour had no clear anatomical relationship with the spleen. The size of this mass and the presence of internal calcified septa led to a moderate index of suspicion for a mucinous cystadenoma. At this juncture, the decision was made to proceed to an open laparotomy with excision and histological analysis.

\section{TREATMENT}

Laparatomy revealed a highly haemorrhagic and calcified mass emanating from the pancreas. This was adherent to the omentum, distal pancreas and splenic vessels. There was 


\section{BMJ Case Reports}

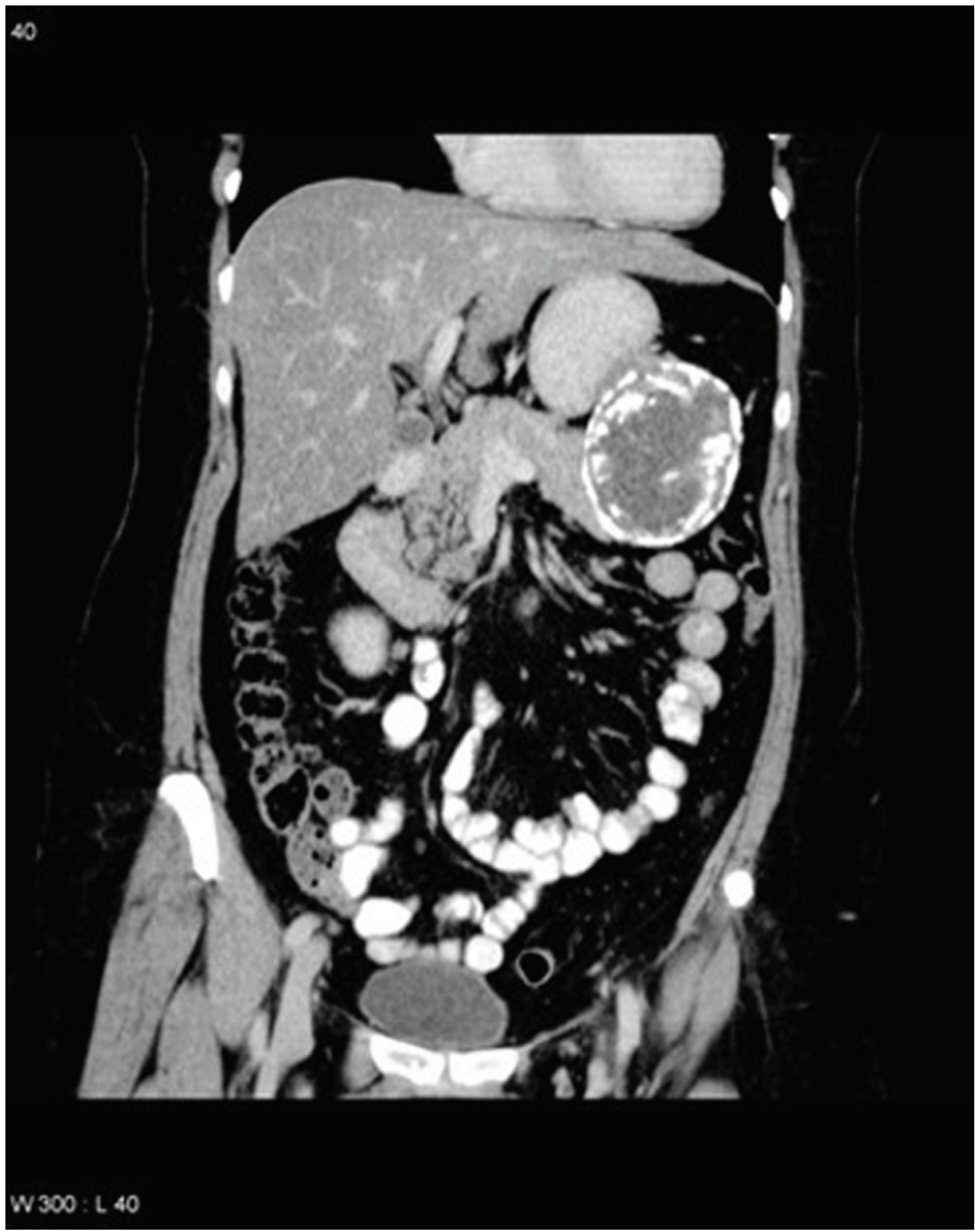

Figure 1 A coronal view of the CT abdomen depicting the $10 \mathrm{~cm}$ mass.

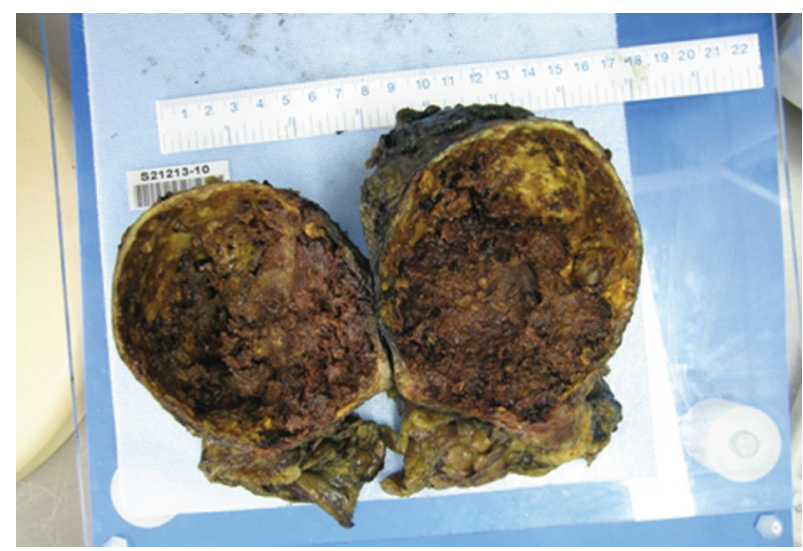

Figure 2 The gross specimen which was densely haemorrhagic and calcified.

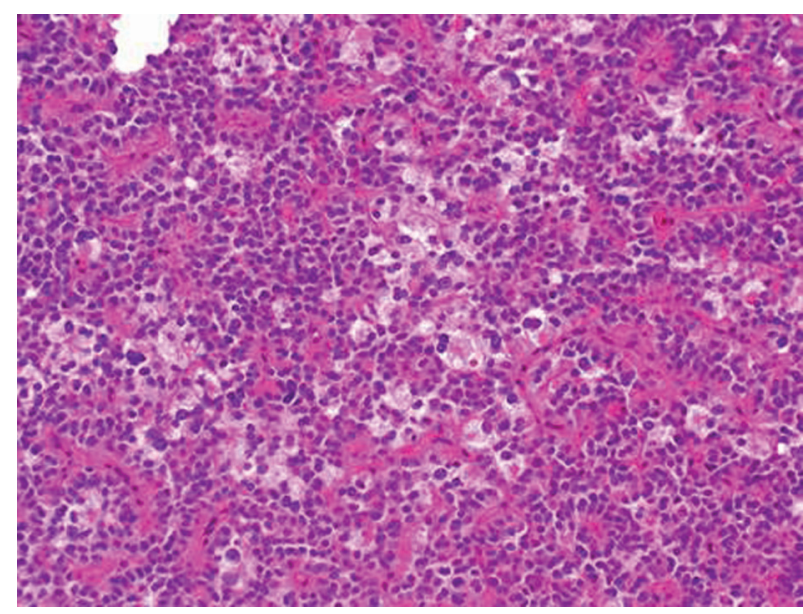

Figure 3 Foam cells observed on histological examination. 
no plane of dissection between the mass, splenic vessels or distal pancreas. Using a vascular stapling device, the spleen was left insitu. Distal pancreatectomy was performed with en bloc resection of the mass. She had an uneventful postoperative course and was discharged well 7 days later.

\section{OUTCOME AND FOLLOW-UP}

The gross specimen weighed 550 grams with dense areas of calcification and ossification. (figure 2). Tumour cells with discohesive polygonal cells were identified histologically. Foam cells were prominent as was nesting, which is a feature of neuroendocrine tumours (figure 3). Neuroendocrine markers were negative. CD 56, CD10, $\beta$ catenin, vimentin, cyclin D1 and epithelial markers were positive. This confirms a characteristic diagnosis of a pseudopapillary pancreatic tumour. ${ }^{4}$ Repeated CT scans at 3,6 and 12 months failed to demonstrate recurrence.

\section{DISCUSSION}

Solid pseudopapillary pancreatic tumours were first described by Franz in 1959. ${ }^{5}$ They account for between 2 and 6 per cent of all pancreatic carcinomas. This tumour has a predilection for non-Caucasian women (M:F 1:10) in the 2 nd or $3 r d$ decade and occasionally occurs in children. Their origin has not been ascertained though they express features of multiple cell lineages. They may be derived from pluripotent stem cells of the pancreas. ${ }^{6}$ There is no known association to any genetic syndromes.

These tumours range in size from 0.5 to $34.5 \mathrm{~cm}$ with a mean diameter of $6.08 \mathrm{~cm}^{7} 8$ and are most commonly found in the body or tail of the pancreas. ${ }^{9}$ Both solid and cystic components with calcifications are features associated with the neoplasm. ${ }^{10}$

With the evolution of imaging techniques the discovery of SPN tumours as incidental findings are increasingly common and are reported to account for up to $50 \%$ of cases. ${ }^{11}$ If patients have symptoms there have been reports of abdominal pain, discomfort, nausea and vomiting. ${ }^{12}$ Obstructive jaundice is uncommon and laboratory values are not affected. ${ }^{9}$

CT is the radiological investigation of choice. Cytology is diagnostic in $75 \%$ of cases. ${ }^{13}$ In one study (Nguyen et al) involving 34 cases of SPT, diagnostic markers were $\beta$ catenin and a loss of membranous expression of E-cadherin. ${ }^{13}$ Most SPTs are also strongly positive for CD10 (96\%), progesterone receptor $(79 \%)$, cytokeratin $(28 \%)$, synapthophysin $(26 \%)$ and chromogranin $(15 \%){ }^{14}$

Although the malignancy rates associated with this neoplasm have not been extensively investigated, in one study (Fasanella and McGrath) involving 62 patients found nine $(15 \%)$ were malignant. ${ }^{14}$ These malignant tumours extended into adjacent blood vessels and organs, recurred locally and metastasis was mainly to liver. ${ }^{15-17}$ No clear factors indicating which tumours are more likely to become malignant have been identified.

Complete surgical excision of localised tumours is curative. The type of surgery depends on location of the tumour. Distal pancreatectomy and central pancreatectomy are preformed when tumours affect the tail and body of the pancreas. ${ }^{18}$ Chemotherapy and radiotherapy have shown no improvement in outcomes. ${ }^{16}$ With complete surgical excision, long-term prognosis is excellent.

\section{Learning points}

- Solid pseudopapillary pancreatic tumours are rare neoplasms accounting for 0.13 to 2.7 per cent of all pancreatic tumours and are most strongly associated with non-Caucasian females under 30 .

- Diagnosis is based on histology with CT providing the best aid for preoperative planning.

- Surgical resection is the preferred management plan and, once diagnosed, SPTs are associated with lowgrade malignancy and an excellent prognosis.

Competing interests None.

Patient consent Obtained.

\section{REFERENCES}

1. Crawford BE 2nd. Solid and papillary epithelial neoplasm of the pancreas, diagnosis by cytology. South Med J 1998;91:973-7.

2. Jemal A, Siegel R, Ward E, et al. Cancer statistics, 2007. CA Cancer J Clin 2007:57:43-66.

3. World Health Organization Classification of Tumours. Pathology and Genetics of Tumours of the Digestive System. In: Aaltonen LA, Hamilton SR, eds. Lyon, France: IARC Press 2000.

4. Tiemann K, Kosmahl M, Ohlendorf J, et al. Solid pseudopapillary neoplasms of the pancreas are associated with FLI-1 expression, but not with EWS/FLI-1 translocation. Mod Pathol 2006;19:1409-13.

5. Franz VK. Tumors of the Pancreas. Atlas of Tumor Pathology: fasc 27-28, ser 7. Washington, DC: Armed Forces Institute of Pathology 1959:32-3.

6. Bardales RH, Centeno B, Mallery JS, et al. Endoscopic ultrasound-guided fine-needle aspiration cytology diagnosis of solid-pseudopapillary tumor of the pancreas: a rare neoplasm of elusive origin but characteristic cytomorphologic features. Am J Clin Pathol 2004;121:654-62.

7. Papavramidis T, Papavramidis S. Solid pseudopapillary tumors of the pancreas: review of 718 patients reported in English literature. J Am Coll Surg 2005;200:965-72.

8. Mao C, Guvendi M, Domenico DR, et al. Papillary cystic and solid tumors of the pancreas: a pancreatic embryonic tumor? Studies of three cases and cumulative review of the world's literature. Surgery 1995;118:821-8

9. Master SS, Savides TJ. Diagnosis of solid-pseudopapillary neoplasm of the pancreas by EUS-guided FNA. Gastrointest Endosc 2003;57:965-8.

10. Gourtsoyiannis NC, ed. Clinical MRI of the Abdomen. New York, USA Springer 2011:242.

11. Romics L Jr Oláh A, Belágyi T, et al. Solid pseudopapillary neoplasm of the pancreas-proposed algorithms for diagnosis and surgical treatment. Langenbecks Arch Surg 2010;395:747-55.

12. Adham M, Giunippero A, Hervieu V, et al. Central pancreatectomy: singlecenter experience of 50 cases. Arch Surg 2008;143:175-80; discussion $180-1$.

13. Nguyen NO, Johns AL, Gill AJ, et al. Clinical and immunohistochemical features of 34 solid pseudopapillary tumors of the pancreas. J Gastroenterol Hepatol 2011;26:267-74

14. Fasanella KE, McGrath K. Cystic lesions and intraductal neoplasms of the pancreas. Best Pract Res Clin Gastroenterol 2009;23:35-48.

15. Salla C, Chatzipantelis $P$, Konstantinou $P$, et al. Endoscopic ultrasound-guided fine-needle aspiration cytology diagnosis of solid pseudopapillary tumor of the pancreas: a case report and literature review. World J Gastroenterol 2007;13:5158-63.

16. Martin RC, Klimstra DS, Brennan MF, et al. Solid-pseudopapillary tumor of the pancreas: a surgical enigma? Ann Surg Oncol 2002;9:35-40.

17. Pasquiou C, Scoazec JY, Gentil-Perret A, et al. [Solid pseudopapillary tumors of the pancreas. Pathology report of 13 cases]. Gastroenterol Clin Biol 1999;23:207-14. 


\section{BMJ Case Reports}

This pdf has been created automatically from the final edited text and images.

Copyright 2012 BMJ Publishing Group. All rights reserved. For permission to reuse any of this content visit http://group.bmj.com/group/rights-licensing/permissions.

BMJ Case Report Fellows may re-use this article for personal use and teaching without any further permission.

Please cite this article as follows (you will need to access the article online to obtain the date of publication).

Cummins D, Sheehan M, Bruzzi J, McAnena 0. Solid pseudopapillary neoplasm of the pancreas. BMJ Case Reports 2012;

10.1136/bcr.01.2012.5589, Published XXX

Become a Fellow of BMJ Case Reports today and you can:

- Submit as many cases as you like

- Enjoy fast sympathetic peer review and rapid publication of accepted articles

- Access all the published articles

- Re-use any of the published material for personal use and teaching without further permission

For information on Institutional Fellowships contact consortiasales@bmjgroup.com

Visit casereports.bmj.com for more articles like this and to become a Fellow

Keep up to date with all published cases by signing up for an alert (all we need is your email address) http://casereports.bmj.com/cgi/alerts/etoc

18. Panieri E, Krige JE, Bornman PC, et al. Operative management of papillary

cystic neoplasms of the pancreas. J Am Coll Surg 1998;186:319-24. 